\title{
慢性閉塞性肺疾患患者の 6 分間歩行距離の違いにおける 身体特性の比較 \\ Comparison of the physical characteristics among chronic obstructive pulmonary disease patients with different 6-minute walking distances.
}

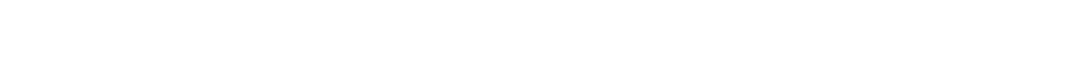 \\ 市丸 勝 昭5) 直 塚 博 行 ${ }^{6)}$ 白仁田秀一 ${ }^{7)}$ 上田真智子 ${ }^{81}$ \\ 田中將英 ${ }^{9}$ 林 真一郎 ${ }^{10}$
}

\author{
Shojiro Egoshi ${ }^{111)}$, Jun Horie ${ }^{2)}$, Kunihiko ANAmi ${ }^{3)}$, Yujiro IMAIZUMI ${ }^{4}$,

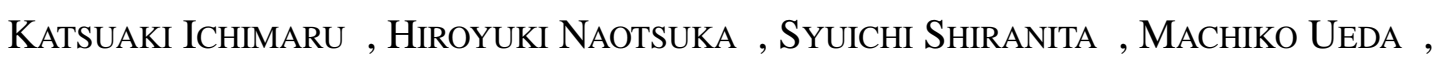 \\ MASAHIDE TANAKA ${ }^{9}$, SHIN-ICHIRO HAYASHI ${ }^{10)}$ \\ 要旨 : 慢性閉塞性肺疾患 (COPD) 患者の6 分間歩行距離 (6MWD) の違いにおける身体 \\ 特性を比較した。対象は安定期 COPD 患者76名とした。方法は，6MWD，Body Mass Index \\ (BMI), 呼吸機能検查, 下肢筋力, 握力, 呼吸筋力, バランス能力, 歩行能力, 長崎大 \\ 学呼吸器疾患 ADL 質問票 (NRADL), St George's Respiratory Questionnaire (SGRQ) を評 \\ 価し，6MWDにて3 群に分類し，各測定項目を検討した。結果，\%努力性肺活量(\%FVC)，
}

\footnotetext{
受付日 : 2012年 7 月19日，採択日：2012年 9 月12日

1 ) 医療福祉専門学校緑生館理学療法学科

干 841-0074 佐賀県鳥栖市西新町1428 566

TEL0942 84 5100

Department of Physical Therapy, Technical School of Medical and Welfare Ryokuseikan 1428-566 Nishishin-machi, Tosu-shi, Saga 841-0074, Japan. $\mathrm{TEL}+81942845100$

2 ) 神戶国際大学 リハビリテーション学部

Faculty of Rehabilitation Sciences, Kobe International University

3 ) 京都橘大学 健康科学部

Faculty of Health Sciences, Kyoto tachibana University

4 ) 佐賀社会保険病院 リハビリテーション科

Department of Rehabilitation, Saga Social Insurance Hospital

5 ) 佐賀県立病院好生館 リハビリテーション室

Room of Rehabilitation, Saga Prefectural Hospital Kouseikan

6 ) 佐賀大学医学部附属病院 先進機能回復センター

Advanced function recovery center, Saga University Hospital

7 ) 長生堂渡辺医院 リハビリテーション科

Department of Rehabilitation, Choseido Watanabe Clinic

8 ) 社会保険浦之崎病院 リハビリテーション科

Department of Rehabilitation, Social Insurance Uranosaki Hospital

9 ) 社会保険浦之崎病院 呼吸器内科

Department of Respiratory Medicine, Social Insurance Uranosaki Hospital

10) 佐賀大学医学部付属病院 呼吸器内科

Department of Respiratory Medicine, Saga University Hospital

11) 佐賀大学大学院医学系研究科

Graduate School of Medical Science, Saga University
} 
$\% 1$ 秒量 $\left(\% \mathrm{FEV}_{1}\right.$ 。 $)$ ，膝伸展筋力，握力，呼吸筋力，片脚立位時間，TUG，CS-30，最速 歩行時間，NRADL，SGRQに有意差か認められた。COPD 患者における6MWD は，呼吸 機能，筋力，身体能力， ADL 能力，健康関連 QOL を反映した。

キーワード：慢性閉塞性肺疾患，6 分間歩行距離，身体特性

\begin{abstract}
The physical characteristics were compared among chronic obstructive pulmonary disease (COPD) patients with different 6-minute walking distances (6MWD). The subjects were 76 patients with stable COPD. The 6MWD, body mass index (BMI), respiratory function test, lower limb muscle strength, grip strength, respiratory muscle strength, balance function, walking ability, Nagasaki University Respiratory ADL Questionnaire (NRADL), and St George's Respiratory Questionnaire (SGRQ) were evaluated. The patients were divided into 3 groups based on the 6MWD, and each measurement item was investigated. Significant differences were noted in the \%forced vital capacity $(\% \mathrm{FVC})$, forced expiratory volume in one second $\left(\% \mathrm{FEV}_{1}\right.$ o), knee extension muscle strength, grip strength, respiratory muscle strength, single leg standing time, TUG, CS-30, time required to walk a specific distance at the maximum walking speed, NRADL, and SGRQ. The 6MWD reflected the respiratory function, muscle strength, physical ability, ADL, and health-related QOL.
\end{abstract}

Key words: COPD, 6MWD, physical characteristics

I .はじめに

慢性閉塞性肺疾患 (COPD) 患者の日常生活におけ る機能障害の重症度を評価する方法として ,6分間歩行 試験 $(6 \mathrm{MWT})$ がある ${ }^{1)}$ 。6MWTは, 特別な機器を必 要とせず, 方法が簡便で実施しやすいため, 国内外を 問わず広く汎用されている評価方法である。しかし， 6 分間歩行距離 $(6 \mathrm{MWD})$ の解釈方法についてはま だ一定の見解が得られておらず，乥の数值が意味する 事項を検討する必要がある。

Cote CG らは, COPD 患者の6MWD を350m以上群， 349〜250m群，249m以下群の3 群に分類し，各群の 生存率を検討した。弚の結果, 調査開始から 9 年後の

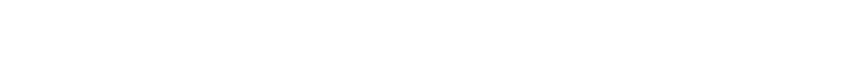
離が短くなるに従い生存率が低下したと報告してい る2)。また， Enfield Kらは, 重症 COPD 患者を対象に 呼吸リハビリテーション (呼吸リハ) 前後での6MWD と生存率に関する検討を行い, 呼吸リ八後の6MWD がより向上した者の方が, 生存率が高值を示したと報 告している3。 にあり，今後数十年間は増加すると予測されている゙。 そのため，死亡率に影響を及ぼす $6 \mathrm{MWD}$ が意味する 事項の分析は重要である。

COPD 患者の6MWD は, 治療によって改善が可能 であるが5), 単に理学療法を行うのではなく, 生存率 に影響を及ぼす $6 \mathrm{MWD} の$ 分類に着目し，弚の分類に
て身体特性を比較することで，これら身体特性の違い を明確化することが可能となる。关うすることで， 6MWD を効率よく改善させるために必要であり，か つ理学療法でのアプローチが可能な身体特性を抽出す ることができ, 光の身体特性に対する理学療法でのア プローチが COPD 患者の生存率改善に寄与する可能 性につながるのではないかと考えた。しかし, 先行研 究において生存率に影響を及ぼす6MWD による分類 で身体特性を比較したものは，これまで公表されてい ない。

弚こで今回，安定期 COPD 患者を対象に, Cote CG らの6MWDの違いにより身体特性，身体機能，身体 能力，QOL にどのような違いがあるのか検討した。

\section{II . 対象と方法}

\section{1. 対 象}

対象は，平成19年10月から平成24年 4 月までに外来 及び入院にて呼吸リハビリが処方された安定期 COPD 患者76名 (男性69名，女性 7 名) である。平均年齢は $73.5 \pm 8$ 8歳，\% 1 秒量 $\left(\% \mathrm{FEV}_{1}\right) 512 \pm 24.4 \%$ であっ た。修正 MRC息切れスケール (mMRC) は, Grade 0 が 4 名, Grade 1 が20名, Grade 2 が32名, Grade 3 が14名，Grade 4 が6名であり，GOLD 重症度分類は， 1 期が11名，2 期が 28 名，3期が19名，4期が18名で あった。 


\section{2. 方 法}

測定項目は，年齢，身長，体重，Body Mass Index(BMI)， 呼吸機能検査, 肢体筋力検査 (膝伸展筋力, 握力, 30 秒椅子立ち上がりテスト (CS- 30) ), 呼吸筋力検査 (最 大吸気口腔内圧 (MIP), 最大呼気口腔内圧 (MEP)), バランス能力検査 (片脚立位時間, Timed Up and Go Test (TUG)) , 歩行能力評価 (6MWT, 最速歩行時間), $\mathrm{ADL}$ 能力評価 (長崎大学呼吸器疾患 ADL 質問票

(NRADL)) , 健康関連 QOL 評価 (St George's Respiratory Questionnaire (SGRQ)) とした。

\section{1 ) 呼吸機能検査}

呼吸機能検査はミナト社製 AutospiroAS-507にて flow-volume 測定を行い, FVC , \%FVC , FEV $10, \mathrm{FEV}_{10}$ $\%$ ％ $\mathrm{FEV}_{1}$ 。を測定した。呼吸機能検査は 2 回実施し， 谷の最良値を採用した。

\section{2 ) 呼吸筋力評価}

呼吸筋力評価はマイクロメディカル社製 microRPM にて MIP と MEP を測定した。MIP，MEPはともに 3 回実施しとの最良值を採用した。

\section{3) 肢体筋力評価}

上肢筋力は竹井機器工業製デジタル式握力計にて握 力を測定, 下肢筋力は股関節, 膝関節 $90^{\circ}$ 屈曲坐位で 椅子に固定した徒手筋力測定装置アニマ社製 $\mu \mathrm{TAS}$ MT- 1 にて大腿四頭筋等尺性最大筋力を測定した。ま た，CS 30は，高さ40cmの椅子に腰掛け，両上肢を胸 部の前で組み, 立ち上がり動作を30秒間反復して行わ せ, 谷の回数を測定した。

\section{4 ) バランス能力評価}

片脚立位時間は, 返脚立位が可能な最大時間をス トップウォッチで両下肢 2 回ずつ測定し，耗のいずれ か一方の最良值を採用した。

TUG は, 椅坐位から立ち上がり，3 m先の目標物 で方向転換し着座するまでの時間をストップウォッチ にて測定した。

\section{5 ) 歩行能力評価}

最速歩行時間は11mの平地を最速で歩行するように 指示し , 中間の $5 \mathrm{~m}$ を測定区間としてストップウォッ チにて测定した。6MWT は30mの平地を 6 分間で最 長距離歩行するよう指示し，产の歩行距離を測定した。 6 ) $\mathrm{ADL}$ 能力・ $\mathrm{QOL}$ 評価

$\mathrm{ADL}$ 能力評価は, NRADL で評価し, QOL の評価 は, SGRQで評価し，弚の合計得点を測定した。

\section{3. 統計学的分析}

6MWD が350m以上群 (長距离隹歩行群)，349から250 $\mathrm{m}$ 群 (中距離歩行群)，249m以下群 (低距離歩行群) の3 群に分類し，各測定項目を1 元配置分散分析を用 いて検定し，光の後多重比較法として Tukey 検定を用 い分析した。なお，帰無仮説の棄却域は有意水準 $5 \%$ とし , 統計解析ソフトは SPSS version 11 for Windows を使用した。

\section{4. 倫理的配慮}

本研究は, 研究の概要, 倫理的配慮, 公表の方法な どについて佐賀大学研究倫理審査委員会の審査を受け， 兴の承認の下実施した（承認番号2011-05 03)。

\section{III. 結 果}

6MWT の分類による 3 群の身体機能の比較では, 年齢 (長距離歩行群 VS 中距離歩行群; p < 0 .01), mMRC (長距離歩行群 VS 低距離歩行群, 中距離歩行 群 VS 低距離歩行群； p <0.001, p <0.001) に有意差 がみられたが, 身長, 体重, BMIには有意差がみら れなかった(表1)。

呼吸機能検査では, FVC（長距離歩行群 VS 低距離 歩行群; p < 0 .001)，\%FVC (長距離歩行群 VS 低距 離歩行群, 中距離歩行群 VS 低距離歩行群; p <0 .001, $\mathrm{p}=0.01$ ), $\mathrm{FEV}_{1}$ 。(長距離歩行群 VS 低距离隹歩行群; $\mathrm{p}$ $<0.001$ ), \% $\mathrm{FEV}_{1}$ 。（長距离隹歩行群 VS 低距离隹歩行群； $\mathrm{p}<0.01$ ), MIP (長距離歩行群 VS 低距離歩行群; p $<0.01$ ), MEP (長距離歩行群 VS 低距離歩行群; p = 0 .02) に有意差がみられたが, $\mathrm{FEV}_{10 \%} \%$ に有意差が みられなかった (表 2 )。

肢体筋力では，CS-30 (長距離歩行群 VS 中距離歩 行群, 長距离隹歩行群 VS 低距离隹歩行群, 中距離歩行群 $\mathrm{VS}$ 低距離歩行群; p $<0.01, \mathrm{p}<0.001, \mathrm{p}=0.01)$ ， 握力 (長距離歩行群 VS 中距離歩行群, 長距離歩行群 VS 低距離歩行群； p = 0 .05, p = 0.01) に有意差が認 められた。膝伸展筋力には, 分散分析において, $\mathrm{p}=$ 0 .04で有意差が認められたが, 弚の後の多重比較検定 において有意差か認められなかった（表 3 )。

バランス能力・歩行能力では, 片脚立位時間 (長距 離歩行群 VS 中距离隹歩行群, 長距离隹歩行群 VS 低距离隹 歩行群; $p=0.01, p<0.001$ ), TUG (長距离隹歩行群 VS 中距離歩行群, 長距離歩行群 VS 低距離歩行群, 中距離歩行群 VS 低距離歩行群; p $<0.01, \mathrm{p}<0.001$, $\mathrm{p}<0.01$ ), 最速歩行時間（長距離歩行群 VS 低距離歩 
表 1 6MWD の違いにおける身体機能の比較

\begin{tabular}{|c|c|c|c|}
\hline & $\begin{array}{c}\geqq 350 \mathrm{~m} \\
\mathrm{n}=42 \\
\text { Mean } \pm \text { SD }\end{array}$ & $\begin{array}{c}\text { 349 250m } \\
\mathrm{n}=18 \\
\text { Mean } \pm \text { SD }\end{array}$ & $\begin{array}{c}249 m \geqq \\
n=16 \\
\text { Mean } \pm \text { SD }\end{array}$ \\
\hline \multicolumn{4}{|c|}{$* *$} \\
\hline 年齢 (歳) & $72.3 \pm 7.7$ & $76.4 \pm 7.0$ & $77.0 \pm 83$ \\
\hline 身長 (cm) & $162.4 \pm 6.7$ & $1598 \pm 73$ & $1634 \pm 81$ \\
\hline \multirow[t]{2}{*}{ 体重 (kg) } & $56.7 \pm 108$ & $\begin{array}{c}55.6 \pm 13.7 \\
* * * \\
\end{array}$ & $52.6 \pm 99$ \\
\hline & \multicolumn{3}{|c|}{$* * *$} \\
\hline mMRC & $15 \pm 0.7$ & $21 \pm 08$ & $3.0 \pm 0.7$ \\
\hline \multirow[t]{2}{*}{ BMI $\left(\mathrm{kg} / \mathrm{m}^{2}\right)$} & $21.4 \pm 3.5$ & $\begin{array}{c}21.6 \pm 43 \\
* * *\end{array}$ & $19.6 \pm 2.9$ \\
\hline & \multicolumn{3}{|c|}{$* * *$} \\
\hline 6MWD (m) & $454.7 \pm 74.9$ & $3078 \pm 262$ & $1461 \pm 57.6$ \\
\hline \multicolumn{4}{|c|}{$\begin{array}{l}{ }^{*}: \mathrm{p}<0.05,{ }^{* *}: \mathrm{p}<0.01,{ }^{* * *}: \mathrm{p}<0.001 \\
\geqq 350 \mathrm{~m}: 6 \mathrm{MWD} \text { が350m以上群, 349〜250m :6MWD が349mから } \\
\text { 250m群, 249m : 6MWD か249m以下群, mMRC : modified Medical } \\
\text { Research Council , BMI : Body Mass Index, 6MWD : } 6 \text { Minutes Walk } \\
\text { Distance }\end{array}$} \\
\hline
\end{tabular}

表 $36 \mathrm{MWD}$ の違いにおける肢体筋力, バランス能力, 歩行 能力の比較

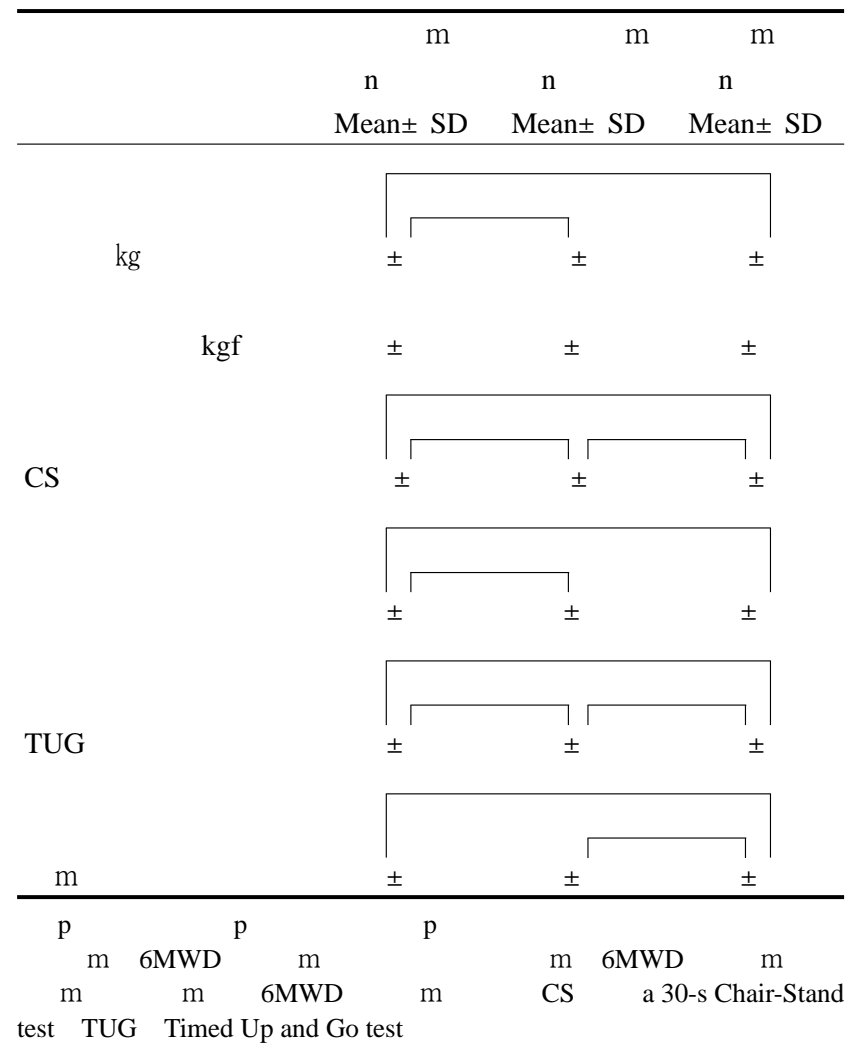

表 2 6MWD の違いにおける呼吸機能の比較

\begin{tabular}{|c|c|c|c|}
\hline & $\begin{array}{c}\geqq 350 \mathrm{~m} \\
\mathrm{n}=42 \\
\text { Mean } \pm \text { SD }\end{array}$ & $\begin{array}{c}\text { 349 250m } \\
\mathrm{n}=18 \\
\text { Mean } \pm \text { SD }\end{array}$ & $\begin{array}{c}249 m \geqq \\
n=16 \\
\text { Mean } \pm \text { SD }\end{array}$ \\
\hline FVC (ml) & $27183 \pm 8161$ & $\begin{array}{l}* * * \\
2200 \begin{array}{l}0 \pm 737.3 \\
* * *\end{array} \\
\end{array}$ & $1842.5 \pm 428.5$ \\
\hline$\% \mathrm{FVC}(\%)$ & $838 \pm 203$ & $\begin{array}{c}77.5 \pm 221 \\
* * * \\
\end{array}$ & $571 \pm 14.0$ \\
\hline $\mathrm{FEV}_{10}(\mathrm{ml})$ & $14571 \pm 709.6$ & $\begin{array}{c}1067 \begin{array}{c}2 \pm \\
* * \\
* *\end{array} \\
\end{array}$ & $798.7 \pm 2973$ \\
\hline$\% \mathrm{FEV}_{1.0}(\%)$ & $578 \pm 24.6$ & $512 \pm 233$ & $34.0 \pm 16.6$ \\
\hline $\mathrm{FEV}_{10} \%(\%)$ & $518 \pm 148$ & $\begin{array}{c}462 \pm 125 \\
*\end{array}$ & $43.3 \pm 118$ \\
\hline $\operatorname{MEP}\left(\mathrm{cmH}_{2} \mathrm{O}\right)$ & $75.7 \pm 372$ & $\begin{array}{c}643 \pm 371 \\
* *\end{array}$ & $471 \pm 275$ \\
\hline $\mathrm{MIP}\left(\mathrm{cmH}_{2} \mathrm{O}\right)$ & $728 \pm 34.7$ & $58.0 \pm 248$ & $42.6 \pm 37.4$ \\
\hline
\end{tabular}

${ }^{*}: \mathrm{p}<0.05,{ }^{* *}: \mathrm{p}<0.01,{ }^{* * *}: \mathrm{p}<0.001$

$\geqq 350 \mathrm{~m}: 6 \mathrm{MWD}$ が350m以上群, 349〜250m : 6MWD が349mから 250m群, 249m?: 6MWD が249m以下群, FVC : Forced Vital Capacity , \%FVC : FVC\%predicted, $\mathrm{FEV}_{10}$ : Forced Expiratory Volume in one second, $\% \mathrm{FEV}_{10}: \mathrm{FEV}_{10} \%$ predicted, $\mathrm{FEV}_{10} \%: \mathrm{FEV}_{10} / \mathrm{FVC}$ ratio\%, MEP : Maximal Expiratory Pressure , MIP : Maximal Inspiratory Pressure

表 4 6MWD の違いにおける ADL 能力, QOL 能力の比較

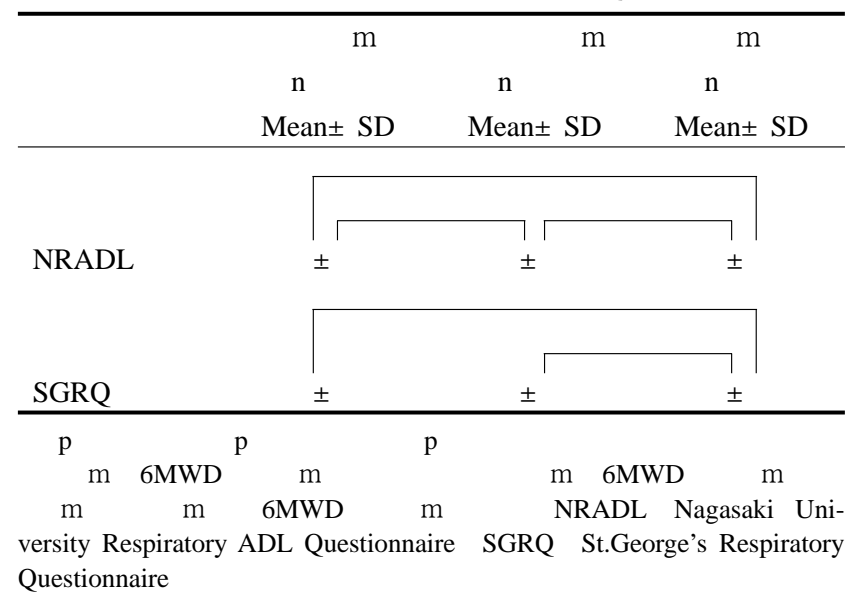

行群, 中距離歩行群 VS 低距離歩行群 ; p $<0.01, \mathrm{p}=$ 0 .01) に有意差か認められた（表 3 )。

$\mathrm{ADL}$ 能力・ $\mathrm{QOL}$ 能力では, NRADL（長距離歩行 群 VS 中距離歩行群，長距離歩行群 VS 低距離歩行群， 中距離歩行群 VS 低距離歩行群; $\mathrm{p}=0.03, \mathrm{p}<0.001$ ， $\mathrm{p}<0.001$ )，SGRQ（長距離歩行群 VS 低距離歩行群， 中距離歩行群 VS 低距離歩行群; $\mathrm{p}<0.001, \mathrm{p}<$ 0 .001) に有意差が認められた（表 4 )。

\section{N. 考 察}

本研究は, Cote CG らが報告した生存率に影響を及 
ぼす6MWD の違いによって COPD 患者の身体特性に どのような影響を及ぼすか検討した。光の結果，年齢， 呼吸困難感, 呼吸機能, 筋力, バランス能力, 歩行能 力, $\mathrm{ADL}$ 能力, $\mathrm{QOL}$ 能力に有意差が認められ, $6 \mathrm{MWD}$ の効率的な改善を考慮した理学療法によるアプローチ すべき身体特性が明らかとなった。

運動耐容能の低下に加齢変化が伴うということは周 知の通りである6。 離歩行群では中距離歩行群よりも有意に年齢が低值を 示し, 長距離歩行群と低距離歩行群での比較でも，有 意差はみられなかったものの, 長距離歩行群で年齢が 低値を示し，COPD 患者においても，加齢による運動 耐容能低下の影響が示唆された。よって, COPD 患者 は，若年齢の方が運動耐容能低下も少なく，アプロー チが行いやすいことが考えられ，病期の早期の段階で のアプローチが必要だと考える。

呼吸困難感の評価である mMRCに関しては， $6 \mathrm{MWD}$ が長距離歩行群と低距離歩行群, 中距離歩行 群と低距離歩行群に有意差が認められた。Spruit MA らは COPD 患者の6MWD 歩行距離の低下に関連する 要因を検討しており，6MWD が350m未満の COPD 患 者は $\mathrm{mMRC}$ が 2 以上であったと報告している7)。今回 の結果からも同樣の結果が得られ, mMRCは運動耐 容能を簡便に評価する指標として有効であることが示 唆された。

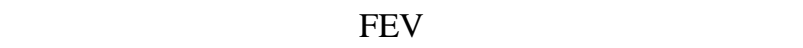
有意差がみられた。COPD の病期分類は，\% $\mathrm{FEV}_{1}$ 。に て分類されるが8), 今回の結果から，運動耐容能が低 下するにつれて，FVC，\%FVC も低下する傾向にあり， 呼吸機能を評価する上では，気流制限のみならず，肺 活量の評価も重要であることが示唆された。

筋力評価においては，握力は6MWD が長距離歩行 群と中距離歩行群, 長距離歩行群と低距離歩行群の 2 群間に有意差がみられたが，膝伸展筋力に関しては， 分散分析では有意差がみられたが, 弚の後の多重比較 検定においては有意差がみられなかった。Colucci M らは, 異なる負荷での上肢筋運動は, 動的肺過膨張に 直接影響すると報告している と，上肢筋の運動は動的肺過膨張をより敏感に反映さ せるため, 動的肺過膨張を生じる者は下肢よりも上肢 筋力の低下を招きやすく，下肢筋力よりも上肢筋力の 方が運動耐容能の低下をより敏感に反映する可能性が 考えられる。よって動的肺過膨張が生じている者には 上肢筋力の低下を念頭に置いた評価，アプローチが必
要だと考えられる。

CS 30に関しては，6MWD での分類 3 群間全てに おいて有意差がみられた。CS 30は本来，高齢者の下 肢筋力を簡便に評価する方法として利用されているも のだが(10)，直塚らは，COPD患者の peakVO ${ }_{2}$ と CS- 30 の関係を検討し，有意な相関を示したと報告してい $3^{11)}$ 。今回の結果からも，CS-30は6MWD に敏感に反 映し，COPD 患者の運動耐容能を簡便に評価する方法 として有効であることが示唆され，CS-30を向上させ るようなアプローチも運動耐容能の向上を図るために は必要だと考える。

また，呼吸筋力に関しては，MIP，MEPの両方に 有意差がみられた。COPD 患者の骨格筋の筋力は，気 流制限か強いものほど低下すると言われており ${ }^{12)}$, 今 回の呼吸筋力に関しても，運動耐容能が低下している ものは気流制限も強いため, 呼吸筋力も低值を示した と考えられる。また，一般的に，呼吸筋トレーニング は，吸気筋トレーニングを行うことが主流ではある が(3 ${ }^{(16)}$ ，今回の結果では MEP にも有意差がみられた ため，吸気筋トレーニングのみではなく，呼気筋力を 強化するようなトレーニング方法も運動耐容能向上の ためには必要であるのではないかと考える。

バランス能力, 歩行能力に関して, TUG では, 3群 間全てにおいて有意差が認められた。TUG はバラン ス能力を評価する方法 ${ }^{17)}$ であり，今回の結果から，運 動耐容能が低值群ほどTUG は高値を示し，バランス 能力が低下する傾向にあることがわかった。COPD 患 者のバランス能力の低下は先行研究によって以前から 指摘されており ${ }^{18)}$ ，今回の結果からも運動耐容能が低 下している者ほどバランス能力の低下がみられること がわかったため, 弚のような患者には転倒に対するア プローチも考慮する必要性があると考えられる。また， TUG は最速時間を評価するため，俊敏な能力が必要 であり，有意差が認められた最速歩行時間の評価にお いても俊敏な動作が必要となる。COPD 患者は収縮速 度が遅い type I 線維だけでなく，収縮速度が速い type

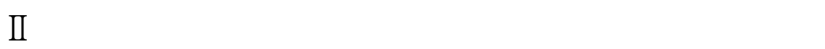
動耐容能が低下している者は, type II 線維の萎縮も考 えられ，俊敏な動作が困難になっていることが考えら れる。光のため, 俊敏な動作能力を向上させるアプロー チも必要であると考えられる。

最後に, ADL 能力と QOL に関してであるが， NRADL では 3 群間全てに有意差か認められた。この ことから，NRADL は ADL 能力のみならず，運動耐 
容能をも敏感に反映する優れた評価であることが示唆 された。また，SGRQでは, 6MWDが長距離歩行群 と中距離歩行群以外に有意差か認められたことから， 6MWD が249m以下になるような運動耐容能が著名に 低下した場合にのみ健康関連 QOL が低下することが 示唆された。

これらの知見から，生存率に影響を及ぼす $6 \mathrm{MWD}$ の分類は, 年齢, 呼吸困難感, 呼吸機能, 筋力, バラ ンス能力, 歩行能力, ADL 能力, QOL に影響を及ぼ すものであり, 非常に多くの身体機能の要素を反映す る優れた評価法であることがわかった。また，6MWD は呼吸リハにより改善が可能であり，6MWD を向上 させる治療としては, ただ単に全身持久カトレーニン グを行うのではなく，今回の生存率に影響を及ぼす 6MWD での分類にも着目し, 光れらの距離別に応じ て，機能低下が生じている身体機能，身体能力を向上 させるために必要なアプローチを実施することも重要 である。光うすることが6MWDのより効率的な向上 を促し, QOL の向上や, 若いては生存率の向上にも つながっていくと考える。ただし，今回の研究では生 存率での分類に応じて解析をしたものの, 対象が光の 生存率に匹敵するかどうかは不明である。また, 実際 に6MWD の分類に応じたアプローチの効果を検証し たわけではないので, 今後追跡して調査し，明らかに していくことが今後の課題である。

\section{文献}

1 ) ATS statement: guidelines for the six-minute walk test. Am J Respir Crit Care Med, 2002, 166 (1): 111-117.

2 ) Cote CG,Pinto-Plata V, Kasprzyk K, et al.: The 6-Min Walk Distance,Peak Oxygen Uptake,and Mortality in COPD.Chest, 2007, 132 (6): 1778-1785.

3 ) Enfield K,Gammon S, Floyd J, et al.: Six-minute walk distance in patients with severe end-stage COPD: association with survival after inpatient pulmonary rehabilitation. J Cardiopulm Rehabil Prev, 2010, 30 (3): 195-202.

4 ) Murray CJ, Lopez AD: Evidence-based health policy-lessons from the Global Burden of Disease Study.Science, 1996, 274: 740-743

5 ) 日本呼吸管理学会呼吸リハビリテーションガイドライン作 成委員会, 日本呼吸器学会ガイドライン施行管理委員会 編: 日本呼吸管理学会/日本呼吸器学会呼吸リハビリ テーションに関するステートメント.日呼会誌, 2002， 40 : 536544

6 ) 鈴木政登, 石山育朗, 塩田正俊 - 他 : 健康人の性・年齢別 最大酸素摂取量 $\left(\mathrm{VO}_{2 \text { max }}\right)$ 基準域および $\mathrm{VO}_{2 \max }$ 判定指標一 反復切断法による $\mathrm{VO}_{2 \max }$ 基準域の設定. 体力科学, 2003, 52(5) : 585- 598 .
7 ) Spruit MA, Watkins ML, Edwards LD, et al.: Determinants of poor 6-min walking distance in patients with COPD: the ECLIPSE cohort. Respir Med, 2010, 104 (6): 849-857.

8 ) 永井厚志・他 : COPD (慢性閉塞性肺疾患) 診断と治療の ためのガイドライン第 3 版, $2009: 33$.

9 ) Colucci M,Cortopassi F, Porto E, et al.: Upper limb exercises using varied workloads and their association with dynamic hyperinflation in patients with COPD. Chest, 2010, 138 (1): 39-46.

10) Jones CJ, Rikli RE, Beam WC: A 30 -s chair-stand test as a measure of lower body strength in community-residing older adults. Res Q Exerc Sport, 1999, 70 (2): 113-119.

11) 直塚博行, 白仁田秀一, 堀江淳 : COPD 患者に対する全身 持久力予測手段としての30秒椅子立ち上がりテスト (CS 30)の有用性についての検討. 理学療法学, 2012, 39(2) : 306

12) Kim HC, Mofarrahi M, Hussain SN: Skeletal muscle dysfunction in patients with chronic obstructive pulmonary disease. Int $\mathrm{J}$ Chron Obstruct Pulmon Dis, 2008, 3 (4): 637-658.

13) Crowe J, Reid WD, Geddes EL, et al.: Inspiratory muscle training compared with other rehabilitation interventions in adults with chronic obstructive pulmonary disease: a systematic literature review and meta-analysis. COPD, 2005, 2 (3): 319-29.

14) Hill K, Jenkins SC, Philippe DL, et al.: High-intensity inspiratory muscle training in COPD. Eur Respir J, 2006, 27 (6): 1119-1128.

15) Weiner P, Magadle R, Beckerman M, et al.: Comparison of specific expiratory,inspiratory,and combined muscle training programs in COPD. Chest, 2003, 124 (4): 1357-1364.

16) Budweiser S, Moertl M, Jorres RA, et al.: Respiratory muscle training in restrictive thoracic disease: a randomized controlled trial.Arch Phys Med Rehabil, 2006, 87 (12): 1559-1565.

17) Podsiadlo D, Richardson S: The timed "Up \& Go": a test of basic functional mobility for frail elderly persons.J Am Geriatr Soc, 1991, 39 (2): 142-148.

18) Ozalevli $S$, Ilgin $D$, Narin $S$, et al.:Association between diseaserelated factors and balance and falls among the elderly with COPD: a cross-sectional study. Aging Clin Exp Res, 2011, 23 (5 -6): 372-377.

19) Gosker HR, Engelen MP, van Mameren H, et al.: Muscle fiber type IIX atrophy is involved in the loss of fat-free mass in chronic obstructive pulmonary disease. Am J Clin Nutr, 2002, 76 (1): 113-119. 